\title{
Preparation and thermal analysis kinetics of the core-nanoshell composite materials doped with $\mathrm{Sm}$
}

\author{
Ruxin Che $\cdot$ Yijun Jiang $\cdot$ Liqiu Wei $\cdot$ \\ Xiaona He
}

Received: 6 August 2013/Accepted: 27 November 2013/Published online: 13 December 2013

(C) The Author(s) 2013. This article is published with open access at Springerlink.com

\begin{abstract}
The core-nanoshell composite materials with magnetic fly-ash hollow cenosphere as core and nano $\mathrm{SmFeO}_{3}$ as shell were synthesized by high-energy ball milling method. The magnetic fly-ash hollow cenosphere, samarium nitrate, and iron nitrate were used as raw materials. The synthesis and growth kinetics of the composite materials were investigated using the thermogravimetry and differential thermal analysis (TG-DTA) at different heating rates. The results show that the precursor of the composite materials decomposes in three steps. The apparent activation energy of each stage was calculated using the Doyle-Ozawa and Kissinger methods. The reaction order, frequency factor, and rate equations were also determined. The activation energy of the nano crystallite growth is calculated to be $16.12 \mathrm{~kJ} \mathrm{~mol}^{-1}$ according to kinetics theory of nano crystallite growth. It can be inferred that the crystallite grows primarily by means of an interfacial reaction during the thermal treatment. The magnetic properties and microwave absorbing properties of samples were analyzed by the vibrating sample magnetometer analysis and vector network analyzer. The results indicated that the exchange coupling interaction happens between ferrite of magnetic fly-ash hollow cenosphere and
\end{abstract}

R. Che $(\bowtie) \cdot$ L. Wei

College of Environmental and Chemical Engineering,

Dalian Jiaotong University, Dalian 116028, China

e-mail: mailjyl@aliyun.com

R. Che $\cdot$ X. He

College of Material Science and Engineering,

Dalian Jiaotong University, Dalian 116028, China

Y. Jiang

Department of Physics, Massachusetts Institute of Technology,

Boston, MA 02139-4307, USA nanosized ferrite coating, which cause outstanding magnetic properties. In the frequency between $1 \mathrm{MHz}$ and $1 \mathrm{GHz}$, the absorbing effectiveness of the composite absorbers can achieve $-32 \mathrm{~dB}$. The magnetic properties of the composite material are better than those of single phase. So it is consistent with requirements of the microwave absorbing material at the low-frequency absorption.

Keywords Magnetic fly-ash hollow cenosphere - The core-nanoshell composite materials · High-energy ball milling - Thermal analysis kinetics - Magnetic properties . Microwave absorbing properties

\section{Introduction}

The core-nanoshell composite materials have a broad application prospect because of its surface effect. However, the high specific surface area makes it become a kind of metastable material. The mean free energy of the material per unit volume has increased with the decrease of the grain size, which leads to the reducing of the thermal stability of the material. For a type of new materials, the thermal stability will influence their application. In recent years, some researches have been done, for example, the synthesis kinetics of nano $\operatorname{In}_{2} \mathrm{O}_{3}$ [1], the grain growth kinetics of FeNiAlGaPBSiC amorphous alloy [2], preparation and thermal analysis of the bacterial cellulose/polyurethane nanocomposites [3], and thermal stability of several polyaniline/rare earth oxide composites [4]. But the kinetics of core-nanoshell composite materials with magnetic fly-ash hollow cenosphere (MFHC) as core are rarely studied.

The MFHC is a by-product of thermal power plant. This is turning waste into treasure for the application of cenosphere. When a coal-burning boiler works, the majority of 
iron minerals in the coal form $\mathrm{Fe}_{2} \mathrm{O}_{3}, \mathrm{Fe}_{3} \mathrm{O}_{4}$ with the carbon, carbon monoxide acting. They combine with the new silicon, aluminum, and calcium cenosphere material. The density is $3.1-4.2 \mathrm{~g} \mathrm{~cm}^{-3}$, and pile density is $1.9-1.8 \mathrm{~g} \mathrm{~cm}^{-3}$. It belongs to the strong magnetic mineral, the mean grain size $<75 \mu \mathrm{m}$ [5]. Application of MFHC relates to various fields such as physical, chemical, mechanical, electrical insulation and other aspects because of its special performance. Its most notable features are high intensity, low density, anti-erode, and good stability. It can be modified to become the high-performance microwave absorbing materials.

The processes of synthesis-drying and baking are needed in the preparation of the composite nanomaterials by high-energy ball milling method. Different condensed matter structures have decisive influences on the material performance, so the nucleation and crystal growth process of the material will affect the microstructure and performance. Therefore, it has very remarkable significance that the related kinetics parameters and grain nucleation growth behavior of the composite nanomaterials are analyzed, which can guide the material synthesis.

In this article, the core-nanoshell composite materials were synthesized by high-energy ball milling method, in which MFHC is core and nano $\mathrm{SmFeO}_{3}$ is shell. The synthesis and growth kinetics of the composite nanomaterial were investigated by the thermogravimetry and differential thermal analysis (TG-DTA) at different heating rates. The apparent activation energy of each stage was calculated using the Doyle-Ozawa and Kissinger methods; the reaction order, frequency factor, and rate equations were also determined. The composite nanomaterials have a strong magnetic property, and then they can be used as magnetic absorbing agent.

\section{Materials and methods}

\section{Pretreatment of MFHC}

MFHC came from the fly-ash hollow cenospheres of thermal power plant. MFHC was screened under 5000 and 7000 head, and then classification has been carried out for each magnetic particle size. The magnetic fields were 0.05 , 0.098 , and $0.2 \mathrm{~T}$ (Tesla).

MFHC was soaked in $\mathrm{CH}_{2} \mathrm{Cl}_{2}$ for $10 \mathrm{~min}$ to remove its surface organic residues. Then ultrasonic cleaning technology was used with $\mathrm{NaOH}$ solution $\left(0.5 \mathrm{~mol} \mathrm{~L}^{-1}\right)$ for 30 min, which solved the problem of corrosion during removing impurities and greasy dirt with acid or alkali liquor. Meanwhile it removed the left liquid in crevices of cenosphere, which increased the surface activity of the particles, broke the unity between the particles, and
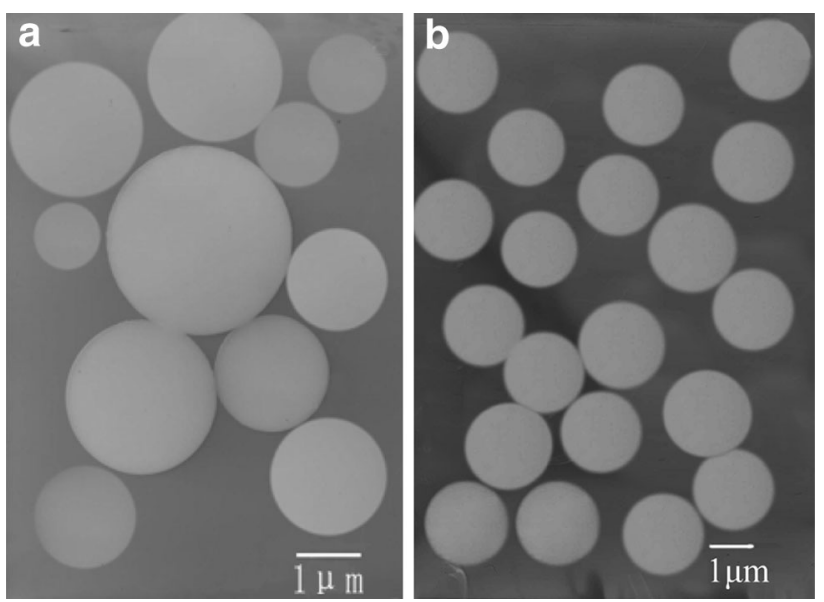

Fig. 1 Transmission electron microscope (TEM) images of MFHC $\mathbf{a}$ before pretreatment and $\mathbf{b}$ after pretreatment

improved the quality of coating processes. The transmission electron microscope (TEM) images of MFHC before and after pretreatment are shown in Fig. 1.

\section{Synthesis}

The core-nanoshell composite materials were prepared through high-energy ball milling at room temperature, using analytical grade $\mathrm{Fe}\left(\mathrm{NO}_{3}\right)_{3} \cdot 9 \mathrm{H}_{2} \mathrm{O}, \mathrm{Sm}_{2} \mathrm{O}_{3}, \mathrm{MFHC}$, and additive as starting chemicals. First, stoichiometric amount starting chemicals were mixed and put into the ball mill with 300 revolutions per minute for $30 \mathrm{~min}$ at room temperature to get a kind of viscid substance. The precursor was got after the viscid substance was dried at $110{ }^{\circ} \mathrm{C}$ for $2 \mathrm{~h}$. Finally, the samples were calcined at $450{ }^{\circ} \mathrm{C}$ for $1 \mathrm{~h}$, and then at $700{ }^{\circ} \mathrm{C}$ for $3 \mathrm{~h}$. The final product was core-nanoshell composite powder.

\section{Characterization}

The thermal analysis was carried out by thermogravimetry and differential thermal analysis (TG-DTA, STA409CD, Netzsch, Germany) with a heating rate of $10{ }^{\circ} \mathrm{C} \mathrm{min}^{-1}$ in the air. (Temperature ranges was $20-900{ }^{\circ} \mathrm{C}$ ).

The crystal structure of sample was examined by X-ray diffractometer (XRD, Smartlab, Rigaku Corporation, Japan) with $\mathrm{Cu}-\mathrm{K} \alpha$ radiation. The width at half-peak of the diffraction crystal surface is measured precisely, and then the grain size of the sample is calculated according to the Sherrer equation:

$D=K \lambda /(\beta \cos \theta)$

where $D$ is the grain size (nm), $K$ is the Sherrer constant, $\beta$ is the physical width value of the diffraction peak, and $\theta$ is the diffraction angle. 


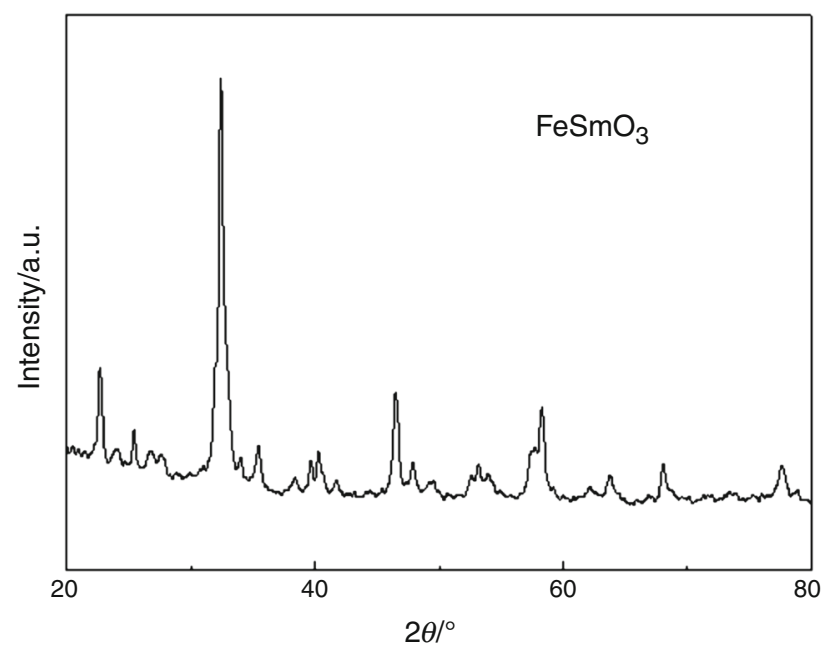

Fig. 2 The XRD pattern of $\mathrm{SmFeO}_{3}$

The microstructure was observed by scanning electron microscope (SEM, JSM-7401F, JEOL Ltd., Japan) and transmission electron microscope (TEM, JEM-2100, JEOL Ltd., Japan).

The magnetic property analysis was conducted by vibrating sample magnetometer (VSM, VersaLab, Quantum Design, USA), and the microwave absorbing property was analyzed by vector network analyzer (VNA, ZVA40, Rohde \& Schwarz, Germany).

\section{Results and discussion}

The thermal decomposition of the precursor

The XRD analysis of the precursor calcined (Fig. 2) shows that the product is pure-phase $\mathrm{SmFeO}_{3}$, because all of the detectable peaks are indexed as the $\mathrm{SmFeO}_{3}$ with orthorhombic crystal system [6] as shown in the standard data (JCPDS: 00-039-1490). No diffraction peaks of other impurities are observed. The average crystallite sizes of $\mathrm{SmFeO}_{3}$ samples are calculated using Sherrer equation to be $28 \mathrm{~nm}$. It shows that the coating layer materials are in nanoscale.

The TG-DTA curves (Fig. 3) of the precursor decomposition are measured under different heating rates. According to the DTA curves, the decomposition processes of the precursor can be divided into three stages, during the temperature range of 70-130, 130-240, and $240-380{ }^{\circ} \mathrm{C}$, respectively. As seen from TG curves, the mass losses of sample under different heating rates are under the same temperature approximately.

The apparent activation energy in the synthesis process of the nanomaterial is calculated by Doyle-Ozawa [7] and Kissinger [8] method. It shows that the diagram of $\log \beta$ versus $1 / T$ is made in a certain conversion $(\alpha)$ (Fig. 4 ), the apparent activation energy can be calculated through the linear slope $-0.4567 E / R$. The temperature of every conversion at different heating rates for the three peaks is given (Table 1 ), and the conversion $(\alpha)$ is acquired through the diagram according to the measured quality change data in the TG test.

The activation energies and the correlation coefficients (Table 2) of the three peaks in different reaction degrees are calculated via each linear slope in Fig. 4. The average apparent activation energies of the three peaks are: $6.849301,8.140784$, and $15.42184 \mathrm{~kJ} \mathrm{~mol}^{-1}$, respectively. The diagram of $\log \left(\beta / T_{\mathrm{m}}^{2}\right)$ versus $1 / T_{\mathrm{m}}$ is made according to the Kissinger method and the activation energy is calculated through the slope $-E / 2.303 R$. Figure 4 is drawn on the base of the data in Table 3 .

The activation energies and the correlation coefficients (Table 3) of the three peaks are calculated via each linear slope in Fig. 5. The energies are 5.305, 6.153, and $16.44 \mathrm{~kJ} \mathrm{~mol}^{-1}$, respectively.

The contrast of the activation energies obtained by two different methods (Table 4) shows that the two results calculated are close [9] and the biggest discrepancy is $2.93 \mathrm{~kJ} \mathrm{~mol}^{-1}$, which shows that the method is accurate [10]. The average apparent activation energies for the precursor decomposition process of the three peaks are $5.76,6.95$, and $16.88 \mathrm{~kJ} \mathrm{~mol}^{-1}$.

The reaction mechanism is further determined after calculating the kinetic parameters using non-isothermal process. Satanva [11] believes that the non-isothermal process can be regarded as an isothermal process, assuming that it is in an infinitely small time interval. According to the Arrhenius formula and Tables 3 and 4, the rate equations of the three peaks, respectively, are:

First peak: $\frac{d \alpha}{d t}=4.241 \times 10^{-3} e^{-5760.60 / R T}(1-\alpha)^{1.248}$

Second peak: $\frac{d \alpha}{d t}=2.187 \times 10^{-3} e^{-6948.20 / R T}(1-\alpha)^{1.331}$

Third peak: $\frac{d \alpha}{d t}=0.588 \times 10^{-3} e^{-16885.27 / R T}(1-\alpha)^{1.010}$

The characterization of composite nanomaterials

The comparison chart of $\mathrm{MFHC}$, nano $\mathrm{SmFeO}_{3}$, and composite nanomaterials is displayed in Fig. 6. It shows that there is the same XRD curve when composite nanomaterials are compared with nano $\mathrm{SmFeO}_{3}$, but the intensity is different. This indicates that the MFHC is completely packaged by the nano $\mathrm{SmFeO}_{3}$. The core-nanoshell composite materials doped with $\mathrm{Sm}$ were prepared successfully. 
Fig. 3 TG-DTA curves of precursor at different heating rates, a TG and b DTA

Fig. $4 \log \beta \sim 1 / T$ plot for $\mathrm{E}$ of each peak using DoyleOzawa method a first peak, b second peak, and c third peak
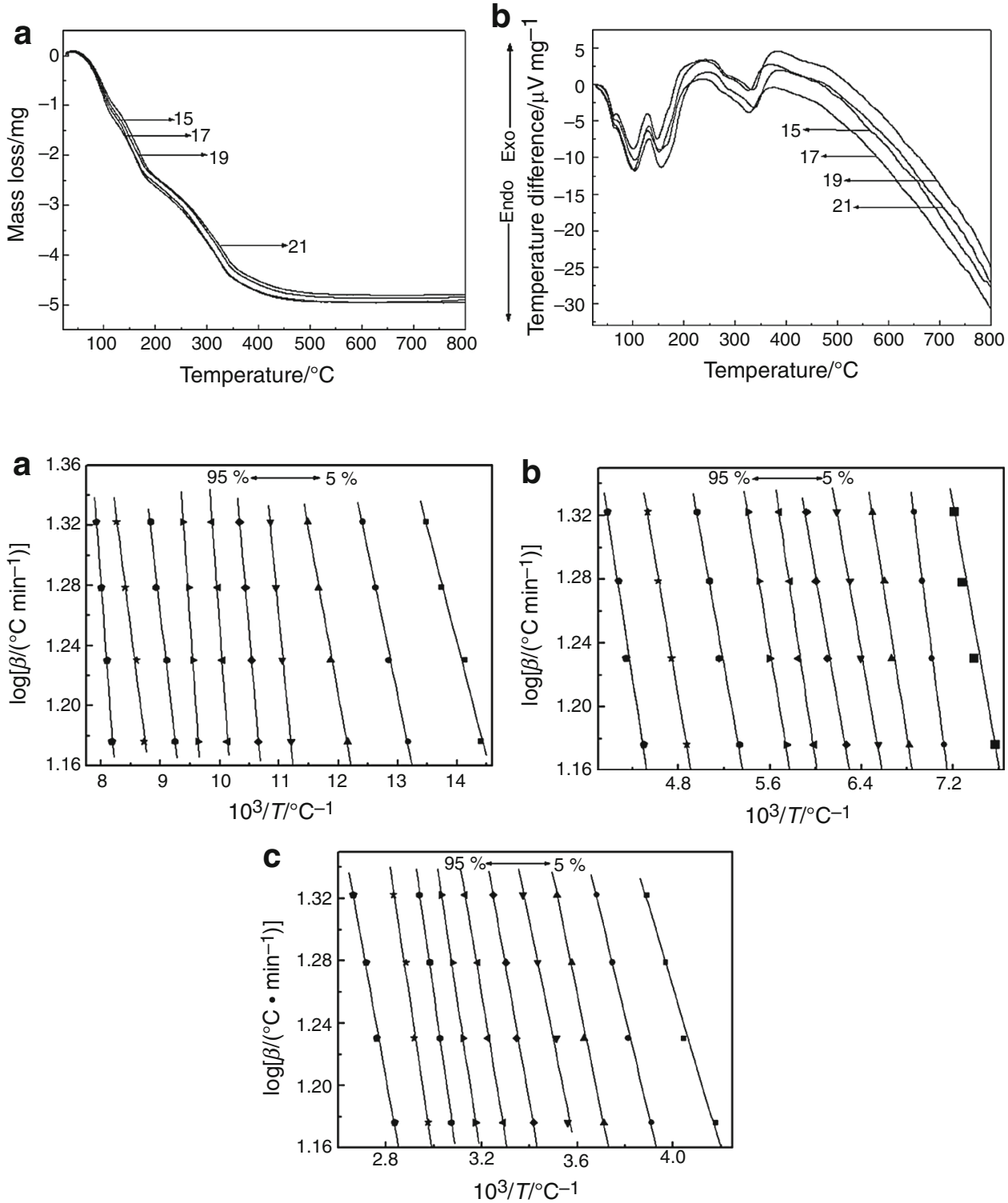

Table 1 Temperatures of each peak at various conversions and different heating rates

\begin{tabular}{|c|c|c|c|c|c|c|c|c|c|c|c|c|}
\hline \multirow[t]{3}{*}{$\alpha / \%$} & \multicolumn{12}{|c|}{$\beta / \mathrm{K} \min ^{-1}$} \\
\hline & \multicolumn{3}{|c|}{$15 / \mathrm{K} \mathrm{min}^{-1}$} & \multicolumn{3}{|c|}{$17 / \mathrm{K} \mathrm{min}^{-1}$} & \multicolumn{3}{|c|}{$19 / \mathrm{K} \mathrm{min}^{-1}$} & \multicolumn{3}{|c|}{$21 / \mathrm{K} \mathrm{min}^{-1}$} \\
\hline & I & II & III & I & II & III & I & II & III & I & II & III \\
\hline 5 & 69.45 & 132.05 & 239.36 & 70.76 & 135.45 & 247.21 & 72.81 & 137.27 & 251.92 & 74.21 & 138.65 & 256.91 \\
\hline 15 & 75.90 & 140.38 & 255.79 & 77.81 & 142.57 & 262.21 & 79.18 & 144.24 & 266.99 & 80.59 & 145.79 & 271.63 \\
\hline 25 & 82.27 & 146.64 & 269.43 & 84.23 & 150.11 & 275.58 & 85.74 & 151.56 & 279.54 & 87.07 & 153.94 & 284.49 \\
\hline 35 & 89.24 & 152.78 & 280.90 & 90.51 & 156.47 & 284.73 & 91.33 & 158.69 & 291.22 & 92.13 & 161.71 & 296.43 \\
\hline 45 & 93.89 & 159.55 & 292.67 & 94.87 & 163.85 & 298.89 & 95.87 & 166.59 & 302.88 & 96.77 & 169.02 & 307.96 \\
\hline 55 & 98.75 & 167.12 & 304.03 & 99.59 & 170.96 & 310.08 & 100.31 & 173.18 & 314.16 & 101.43 & 176.03 & 319.62 \\
\hline 65 & 103.84 & 174.10 & 315.11 & 104.76 & 178.65 & 320.38 & 105.55 & 181.65 & 325.05 & 106.65 & 184.92 & 330.11 \\
\hline 75 & 108.21 & 187.41 & 325.25 & 109.77 & 193.95 & 330.56 & 112.09 & 197.01 & 335.15 & 113.14 & 201.36 & 340.21 \\
\hline 85 & 114.68 & 205.17 & 336.0 & 116.32 & 210.97 & 342.80 & 118.96 & 216.32 & 346.72 & 121.09 & 220.60 & 353.21 \\
\hline 95 & 122.15 & 222.29 & 352.65 & 123.43 & 230.24 & 362.16 & 124.93 & 233.69 & 368.09 & 126.27 & 239.17 & 375.51 \\
\hline
\end{tabular}


Table 2 Activation energies and linear related coefficients of each peak at different degrees

\begin{tabular}{|c|c|c|c|c|c|c|}
\hline$\alpha / \%$ & $E / \mathrm{kJ} \mathrm{mol}^{-1}$ & $\gamma$ & $E / \mathrm{kJ} \mathrm{mol}^{-1}$ & $\Gamma$ & $E / \mathrm{kJ} \mathrm{mol}^{-1}$ & $\gamma$ \\
\hline 5 & 2.776916 & 0.99518 & 7.453291 & 0.99916 & 9.3715 & 0.99485 \\
\hline 15 & 3.494902 & 0.99846 & 10.09386 & 0.99889 & 11.7177 & 0.99864 \\
\hline 25 & 3.974045 & 0.99837 & 8.359511 & 0.99004 & 13.7435 & 0.99776 \\
\hline 35 & 7.598927 & 0.99673 & 7.498438 & 0.99692 & 13.75551 & 0.99255 \\
\hline 45 & 8.339486 & 0.99962 & 7.549593 & 0.99416 & 15.93222 & 0.99772 \\
\hline 55 & 10.04834 & 0.99186 & 8.920574 & 0.99617 & 16.87121 & 0.99793 \\
\hline 65 & 10.56936 & 0.99555 & 7.987047 & 0.99752 & 18.56296 & 0.9995 \\
\hline 75 & 6.253613 & 0.99274 & 7.286719 & 0.99123 & 19.82034 & 0.99945 \\
\hline 85 & 5.576952 & 0.99370 & 7.748568 & 0.99925 & 18.80799 & 0.99521 \\
\hline 95 & 9.860473 & 0.99828 & 8.510245 & 0.99007 & 15.63549 & 0.99724 \\
\hline Average & 6.849301 & 0.99605 & 8.140784 & 0.99534 & 15.42184 & 0.99709 \\
\hline
\end{tabular}

Table 3 Peak maximum temperature $\left(T_{\max }\right)$, peak shape index $(I)$, reaction order $(n)$, frequency factor $(A)$, and active energy $(E)$ at different heating rates

\begin{tabular}{|c|c|c|c|c|c|c|c|c|c|c|c|c|}
\hline \multirow[t]{3}{*}{$\beta /^{\circ} \mathrm{C} \min ^{-1}$} & \multicolumn{12}{|c|}{ Peak number } \\
\hline & \multicolumn{4}{|l|}{ I } & \multicolumn{4}{|l|}{ II } & \multicolumn{4}{|l|}{ III } \\
\hline & $T_{\max } /{ }^{\circ} \mathrm{C}$ & $I$ & $n$ & $A \times 10^{3}$ & $T_{\max } /{ }^{\circ} \mathrm{C}$ & $I$ & $n$ & $A \times 10^{3}$ & $T_{\max } /{ }^{\circ} \mathrm{C}$ & $I$ & $n$ & $A \times 10^{3}$ \\
\hline 15 & 100.85 & 0.93 & 1.2151 & 4.016 & 147.96 & 1.67 & 1.628 & 1.15 & 324.96 & 0.6 & 0.9759 & 0.52 \\
\hline 17 & 100.29 & 0.92 & 1.2085 & 4.018 & 152.02 & 0.98 & 1.247 & 2.14 & 326.77 & 0.85 & 1.1616 & 0.49 \\
\hline 19 & 103.93 & 0.91 & 1.2019 & 4.307 & 151.39 & 0.77 & 1.109 & 2.71 & 334.02 & 0.58 & 0.9595 & 0.63 \\
\hline 21 & 103.50 & 1.18 & 1.3687 & 4.625 & 155.56 & 1.13 & 1.339 & 2.35 & 337.83 & 0.56 & 0.9429 & 0.70 \\
\hline \multirow[t]{2}{*}{ Average } & & 0.98 & 1.2486 & 4.241 & & 1.13 & 1.331 & 2.18 & & 0.65 & 1.010035 & 0.58 \\
\hline & \multicolumn{4}{|c|}{$E=5.3051 \mathrm{~kJ} \mathrm{~m}$} & $\begin{array}{l}E=6.15 \\
r=0.98\end{array}$ & \multicolumn{3}{|c|}{$E=6.15$} & \multicolumn{3}{|l|}{$E=16$} & \\
\hline
\end{tabular}

Figure 7 is the $\mathrm{XRD}$ pattern of $\mathrm{SmFeO}_{3}$ samples calcined at different temperatures. Figure 7 shows that the nano $\mathrm{SmFeO}_{3}$ is prepared successfully as a face-centered orthorhombic. The crystallization of $\mathrm{SmFeO}_{3}$ is imperfect at $600{ }^{\circ} \mathrm{C}$, it shows that the lower temperature is not conducive to the formation of crystals. The crystallization is very well at 700 and $800{ }^{\circ} \mathrm{C}$, they both have similar curves, but the particle diameters are different. The particle size becomes larger as the temperature rises. There are miscellaneous peaks except $\mathrm{SmFeO}_{3}$ at $900{ }^{\circ} \mathrm{C}$, this indicates that some other phase transitions have occurred.

In the synthesis process of the nanocrystalline $\mathrm{SmFeO}_{3}$, temperature control is the key in order to limit the particle size and retain a perfect crystal form and excellent performance. $700{ }^{\circ} \mathrm{C}$ is suitable as tempering temperature based on XRD results. The MFHC coated is calcined at $450{ }^{\circ} \mathrm{C}$ for $1 \mathrm{~h}$, and then at $700{ }^{\circ} \mathrm{C}$ for $3 \mathrm{~h}$. Figure $8 \mathrm{a}, \mathrm{b}$ shows the SEM images of MFHC before and after being coated. Figure $8 \mathrm{~b}$ shows that the nanocrystalline $\mathrm{SmFeO}_{3}$ is coated on the surface of MFHC. Coating layer is formed preferably, in which integrity and particle size distribution are more even. However, the high-temperature calcining promotes agglomeration of nanocrystalline grain and causes particles of the coating layer to become larger in SEM.

The result of XRD above shows that the size of nanocrystalline grain $\mathrm{SmFeO}_{3}$ is $28 \mathrm{~nm}$. The reason for the difference between XRD and SEM is that XRD only reflects the grain size, that is, the particle size is reflected by XRD only when the grain is particle. A particle is composed of several grains because agglomeration occurs in the sample measured in this thesis. So, the size shown between XRD and SEM has differences.

The influence of different calcination temperatures on the grain size is researched using the XRD data of different calcination temperatures, and then the diagram of the relationship between $\ln D$ and $1 / T$ is displayed in Fig. 9. The activation energy of the nano crystallite growth has been calculated via the straight slope $-E / R$ as $16.12 \mathrm{~kJ} \mathrm{~mol}^{-1}$. It can be inferred that the crystallite growth mechanism is diffusion mechanism and it is an interfacial reaction because the activation energy is lower. 
Fig. 5 Relationship for $1 \mathrm{~g}$ $\left(\beta / T_{\mathrm{m}}^{2}\right) \sim 1 / T_{\mathrm{m}}$ at different heating rates of every peak. a First peak, b second peak, and c third peak
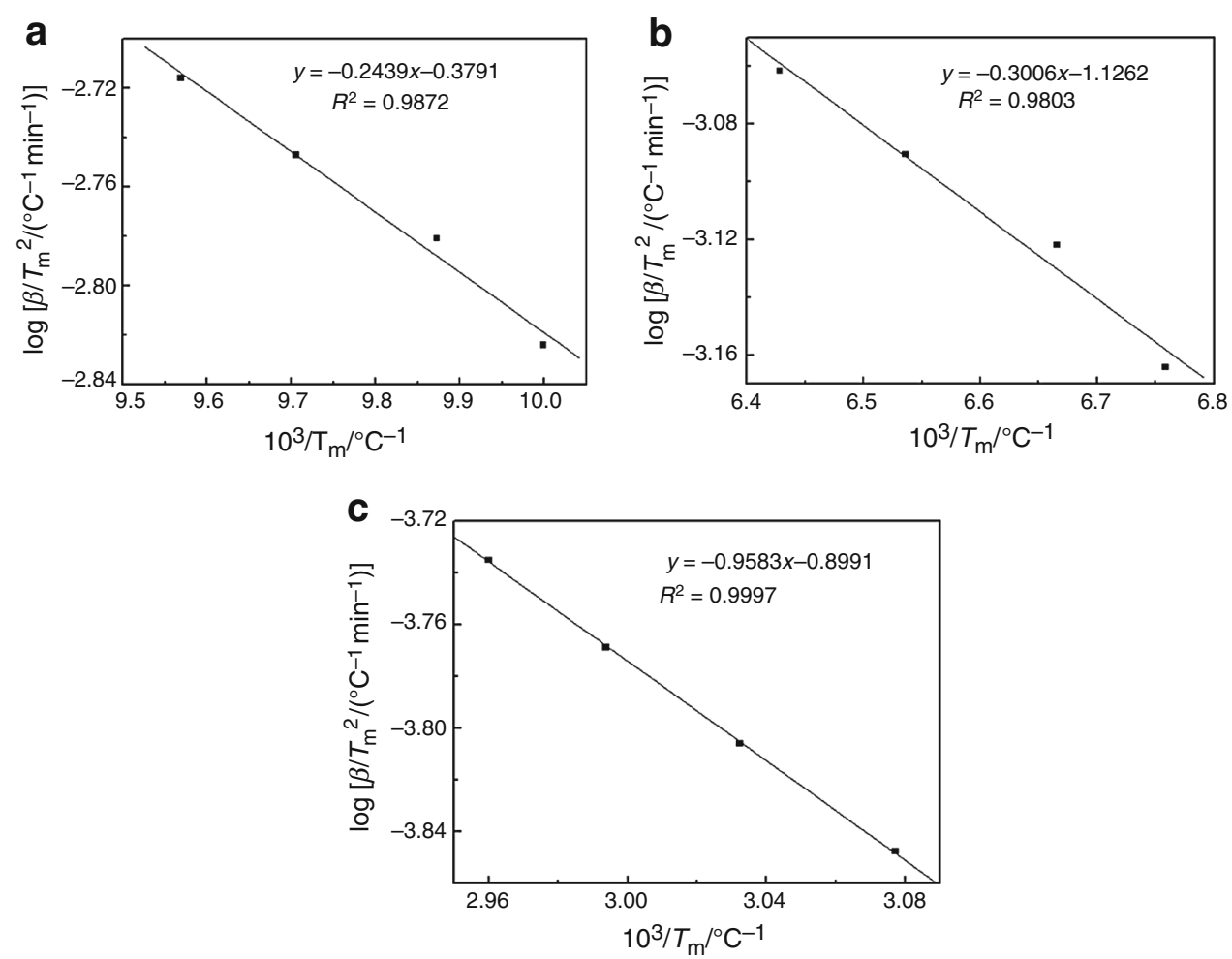

Table 4 Activation energies obtained by two different methods

\begin{tabular}{llll}
\hline Method & $\begin{array}{l}\text { The first } \\
\text { thermal peak } \\
E / \mathrm{kJ} \mathrm{mol}^{-1}\end{array}$ & $\begin{array}{l}\text { The second } \\
\text { thermal peak } \\
E / \mathrm{kJ} \mathrm{mol}^{-1}\end{array}$ & $\begin{array}{l}\text { The third } \\
\text { thermal peak } \\
E / \mathrm{kJ} \mathrm{mol}^{-1}\end{array}$ \\
\hline $\begin{array}{l}\text { Doyle-Ozawa } \\
\text { Kissinger }\end{array}$ & 6.84 & 8.14 & 15.42 \\
Average & 4.67 & 5.75 & 18.35 \\
\hline
\end{tabular}

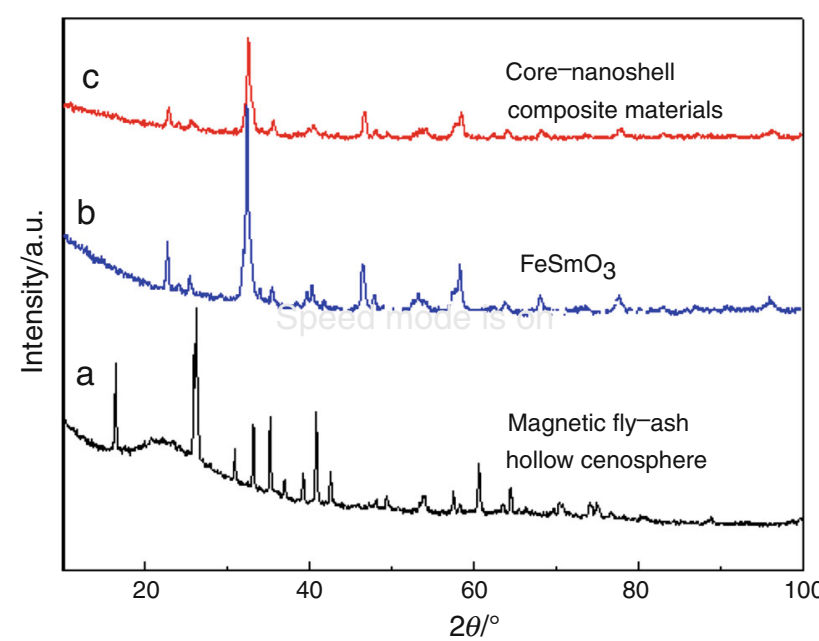

Fig. 6 The comparison XRD pattern of samples

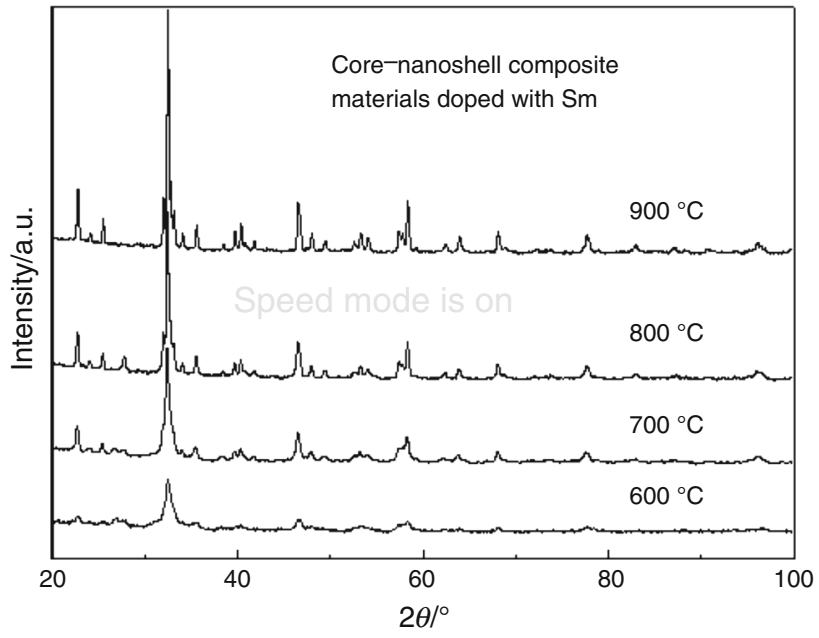

Fig. 7 The XRD pattern of $\mathrm{SmFeO}_{3}$ samples calcined at different temperatures

The magnetic properties of the core-nanoshell composite materials

Figure 10 shows the hysteresis loop curve of MFHC, $\mathrm{SmFeO}_{3}$, and the composite nano-absorbents. Figure 10a shows that the MFHCs themselves have some magnetism; in view of their low density, low cost, and the characteristics of changing waste into treasure, its surface modification can be done with a coating material doped with rare earth element. 
Fig. 8 The SEM image of cenospheres. a Before being coated and $\mathbf{b}$ After being coated
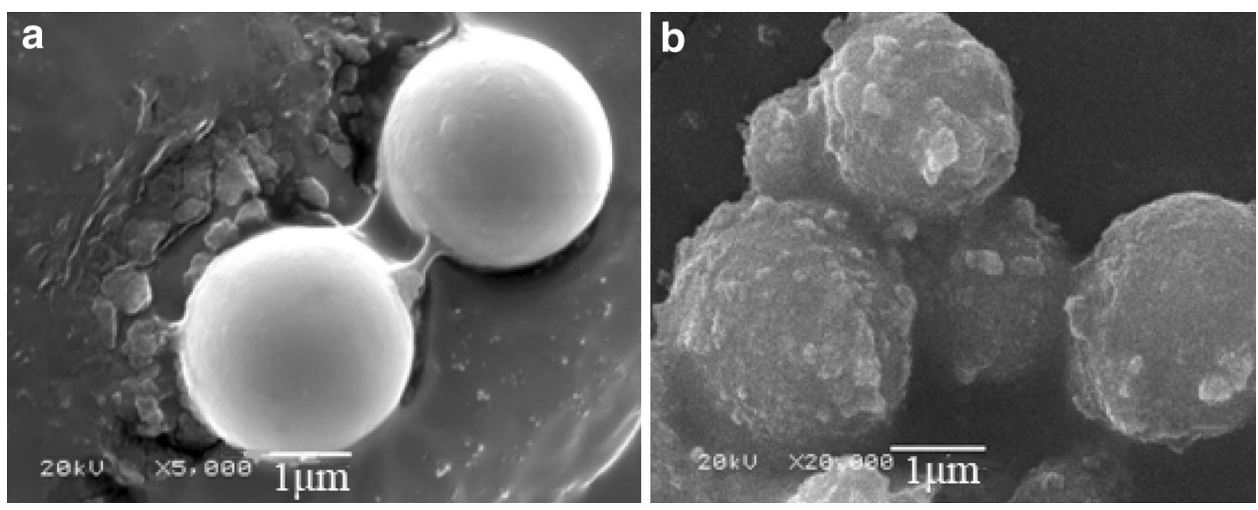

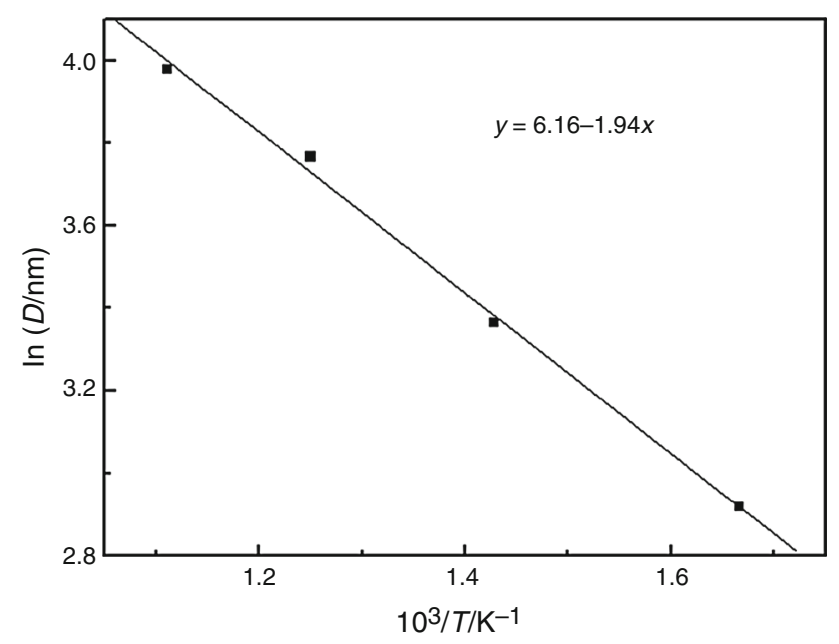

Fig. 9 Relationship between $\ln D$ and $1 / T$ for nanocrystal $\mathrm{SmFeO}_{3}$

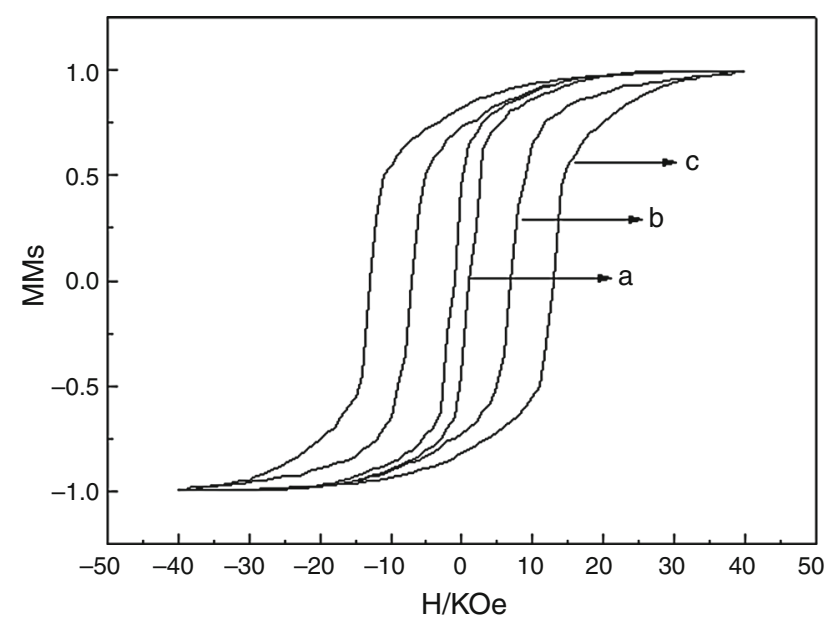

Fig. 10 Hysteresis loop curves of samples. a Hysteresis loop curve of cenosphere, $\mathbf{b}$ hysteresis loop curve of $\mathrm{SmFeO}_{3}$, and $\mathbf{c}$ hysteresis loop curve of core-nanoshell composite materials

Figure 10b shows that $\mathrm{SmFeO}_{3}$ has a strong magnetism. The magnetic variation of the perovskite material $\mathrm{SmFeO}_{3}$ comes from the magnetic moment of the rare earth and iron element. It reveals the interaction mechanism of the spin- lattice coupling in the process of magnetical ordering from the microscope. The lattice structure will have a significant change with the increase of the degree of magnetic order, since the spin-lattice coupling is stronger in the perovskite material $\mathrm{SmFeO}_{3}$. Conversely, the ideal perovskite type of oxide crystal structure $\mathrm{ABO}_{3}$ is usually distorted, and there is the tolerance factor $t$. It will help to promote the ferromagnetic phase transition, causing the enlargement of ferromagnetic coupling, if A, B-site substitution causes a significant change in the lattice structure (that is, the $t$ value becomes larger). These will improve the magnetic properties of materials.

Figure $10 \mathrm{c}$ is a smooth hysteresis loop. It shows that the saturation magnetization, residual magnetization, and coercivity of the composite nano-absorbents have increased exponentially compared with cenosphere and $\mathrm{SmFeO}_{3}$, while the energy product also increases greatly, so it is more suitable for permanent magnet materials. So, it can be considered that the exchange coupling happens between ferrites of $\mathrm{MFHC}$ and $\mathrm{SmFeO}_{3}$. Grain exchange coupling interaction can prevent their directions of magnetic moment from changing along the easy magnetization when two neighboring grains contact directly $[12,13]$. So, the magnetic moment at the interface changes continuously from one grain direction of easy magnetization to another grain direction of easy magnetization. The magnetic moment along the direction of the external magnetic field will increase when the magnetic moment arranges from chaotic to parallel, and the remanence increasing effect will be produced. The ferrites of $\mathrm{MFHC}$ and $\mathrm{SmFeO}_{3}$ array get closer because MFHC is coated by solid-phase method. It leads to the magnetic moment orientation array from one $\mathrm{SmFeO}_{3}$ nanoparticle magnetic moment direction of easy magnetization to another $\mathrm{SmFeO}_{3}$ nanoparticle through ferrites of MFHC. The exchange coupling interaction improves magnetic properties of the composite nano-absorbents. Therefore, the composite nano-absorbents are of both low density and high magnetic characteristics, and they could be expected to replace the single-phase magnetic material. 
Table 5 Serial number of samples

\begin{tabular}{ll}
\hline Sample serial number & Absorbent name \\
\hline Sample 1 & Magnetic fly-ash hollow cenosphere $_{\text {Sample 2 }}$ \\
Sample 3 & $\begin{array}{l}\text { Magnetic fly-ash hollow cenosphere } \\
\text { (had not been pretreated) }+\mathrm{FeSmO}\end{array}$ \\
Sample 4 & $\begin{array}{c}\text { Magnetic fly-ash hollow cenosphere } \\
\text { (had been pretreated) }+\mathrm{FeSmO}_{3}\end{array}$ \\
\hline
\end{tabular}

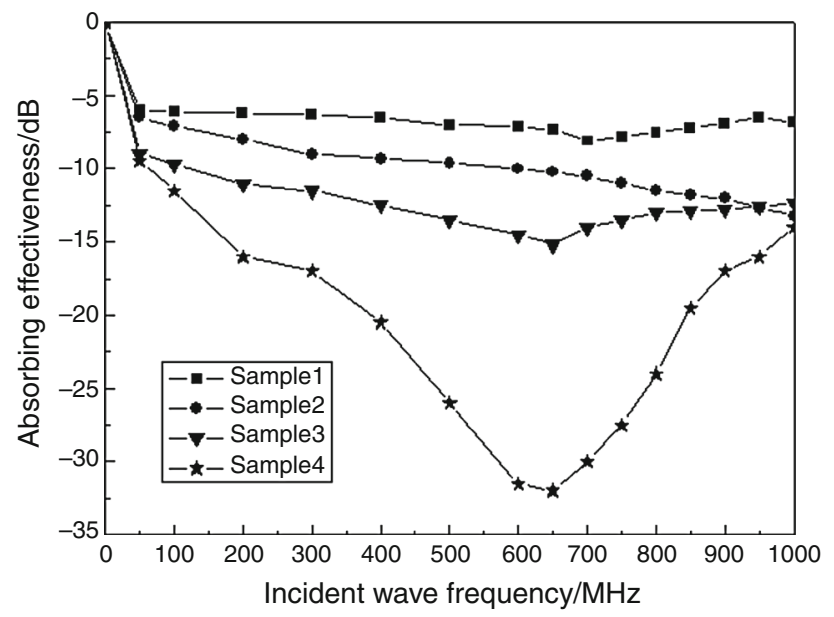

Fig. 11 Relationship of absorbing effectiveness and frequency on samples

Microwave absorbing properties of the core-nanoshell composite particles

Table 5 is the sample serial number. The relationship of absorbing effectiveness and frequency on samples has been shown in Fig. 11. It shows that the absorbing effectiveness of samples has a difference at the same frequency because the component and structure of absorbent is different. Material composition and structure will greatly affect the performance.

The absorbing effectiveness of the single material has some changes with frequency rise, but that of the composite particles has obvious changes. Microwave absorbing properties of the core-nanoshell composite particles are much stronger than the single material, which possibly implies the existence of exchange coupling action between ferrite of cenosphere and $\mathrm{SmFeO}_{3}$ nanoparticles.

Two kinds of mechanisms could be proposed to explain the stronger microwave absorbing properties for the corenanoshell composite particles [5]. The first mechanism is that the exchange coupling could exist between $\mathrm{SmFeO}_{3}$ and ferrite of MFHC. The range of effective exchange coupling is equal to the thickness of magnetic domain wall (about $10 \mathrm{~nm}$ ). When grain size is nano-level, the effect of remanence increase is notable, so the magnetic loss can be increased, and it is better to improve absorbing properties. The second mechanism is the dipole polarization. The nanocomposite is such a perfect system, because the polarized cores can play the role of dipoles, especially at low-frequency, as demonstrated in the $\mathrm{SmFeO}_{3}$ nanoparticles which have coated MFHC. Considering the nanoparticles on coreshell type microstructure, it is reasonable that the dipole polarization is dominant at $1 \mathrm{MHz}$ and $1 \mathrm{GHz}$ frequency and the weak space charge polarization mainly works at higher frequencies. Sample 3 had not been pretreated, so it contains more impurities and the coating is uneven. Its microwave absorbing properties is poorer than sample 4 .

\section{Conclusions}

(1) The core-nanoshell composite materials with MFHC as core and nano $\mathrm{SmFeO}_{3}$ as shell were synthesized by high-energy ball milling method. The average reaction activation energies of the three peaks were calculated, respectively, as $6.07,7.14$, and $15.93 \mathrm{~kJ} \mathrm{~mol}^{-1}$ using Doyle-Ozawa and Kissinger method. The rate equations calculated through the Kissinger method are:

First peak $: \frac{\mathrm{d} \alpha}{\mathrm{d} t}=4.241 \times 10^{-3}$

$$
e^{-5760.60 / R T}(1-\alpha)^{1.248}
$$

Second peak $: \frac{\mathrm{d} \alpha}{\mathrm{d} t}=2.187 \times 10^{-3}$

$$
e^{-6948.20 / R T}(1-\alpha)^{1.331}
$$

Third peak $: \frac{\mathrm{d} \alpha}{\mathrm{d} t}=0.588 \times 10^{-3}$

$$
e^{-16885.27 / R T}(1-\alpha)^{1.010} 1
$$

(2) The nanocrystalline $\mathrm{SmFeO}_{3}$ was obtained from the precursor after preheating at $450{ }^{\circ} \mathrm{C}$ for $1 \mathrm{~h}$ and then annealing at $700{ }^{\circ} \mathrm{C}$ for $3 \mathrm{~h}$; it is crystallized completely and the particle is uniform. The nanocrystal $\mathrm{SmFeO}_{3}$ has very low grain growth activation energy of only $16.12 \mathrm{~kJ} \mathrm{~mol}^{-1}$.

(3) The magnetic properties and microwave absorbing properties of samples were analyzed. The results indicated that the exchange coupling interaction happens between ferrite of MFHC and the coating of nanosized perovskite doped with $\mathrm{Sm}$, which causes outstanding magnetic properties. In the frequency between $1 \mathrm{MHz}$ and $1 \mathrm{GHz}$, the absorbing effectiveness of the core-nanoshell composite materials can achieve $-32 \mathrm{~dB}$. The magnetic properties of the composite material are better than those of single-phase, so it is consistent with requirements of the microwave absorbing material at low-frequency absorption. 
Acknowledgements This work was supported by the National Natural Science Foundation of China (No. 20976018), the Science Research Plan Project of Higher Education Department of Liaoning Province (No. L2013176), the Key Laboratory of Industrial Ecology and Environmental Engineering China Ministry of Education (KLIEEE-12-03), and the National Project of China "Innovation and Entrepreneurship Training Program of Undergraduate students" (201310150002).

Open Access This article is distributed under the terms of the Creative Commons Attribution License which permits any use, distribution, and reproduction in any medium, provided the original author(s) and the source are credited.

\section{References}

1. Zhang XC, Yang HM, Huang $\mathrm{CH}$. Synthesis of indium oxide $\left(\mathrm{In}_{2} \mathrm{O}_{3}\right)$ nanocrystallites and calcination kinetics. Chin J Rare Mater. 2004;285:862-6.

2. Fu MX, Xu JJ, Wang FF. Crystallization kinetics of FeNiAlGaPBSiC amorphous alloy. Rare Met Mater Eng. 2009;138:1410-3.

3. Pinto ERP, Barud HS, Polito WL, Ribeiro SJL, Messaddeq Y. Preparation and characterization of the bacterial cellulose/polyurethane nanocomposites. J Therm Anal Calorim. 2013;114:549-55.

4. Wang SX, Huang ZH, Wang JH, Li YS, Tan ZC. Thermal stability of several polyaniline/rare earth oxide composites (I): polyaniline/ $\mathrm{CeO}_{2}$ composites. J Therm Anal Calorim. 2012;107:1199-203.
5. Che RX, Gao H, Yu B, Wang CX, Wei LQ. Study on preparation of the core-nanoshell composite absorbers by high-energy ball milling at room temperature. J Nanosci Nanotechnol. 2012;12: 1594-8.

6. Feng W, Sun E, Fujii A, Wu H, Nihara K, Yoshino K. Synthesis and characterization of photoconducting polyaniline- $\mathrm{TiO}_{2}$ nanocomposite. Bull Chem Soc Jpn. 2000;73:2627-33.

7. Ozawa T. A new method of analyzing thermogravimetric data. Bull Chem Soc Jpn. 1965;38(11):1881-6.

8. Kissinge HE. Reaction kinetics in differential thermal analysis. Anal Chem. 1957;29(11):1702-6.

9. Zhou K, Wu W, Li Y, Wu X, Liao S. Preparation of magnetic nanocrystalline $\mathrm{Mn}_{0.5} \mathrm{Mg}_{0.5} \mathrm{Fe}_{2} \mathrm{O}_{4}$ and kinetics of thermal decomposition of precursor. J Therm Anal Calorim. 2013;114:205-12.

10. Shaaban ER, Hassaan MY, Mostaf AG, Biskulova SA, Pokhodenko VD. Crystallization kinetics of new compound of $\mathrm{V}_{2} \mathrm{O}_{5}$ $\mathrm{PbO}-\mathrm{Li}_{2} \mathrm{O}-\mathrm{Fe}_{2} \mathrm{O}_{3}$ glass using differential thermal analysis. J Alloy Compd. 2009;482:440-6.

11. Xu CQ, Tian YW, Zhai YC. Kinetic study of spinel $\mathrm{LiMn}_{2} \mathrm{O}_{4}$ synthesized by solid reaction with soft-chemical method. Acta Metall Sin. 2005;18(4):512-8.

12. Parkin SSP. Systematic variation of the strength and oscillation period of indirect magnetic exchange coupling through the $3 \mathrm{~d}, 4 \mathrm{~d}$ and 5d transition metals. Phys Rev Lett. 1991;67:3598-601.

13. Seino S, Kinoshita T, Otome Y. Magnetic composite nanoparticle of $\mathrm{Au} / \gamma-\mathrm{Fe}_{2} \mathrm{O}_{3}$ synthesized by gamma-ray irradiation. Chem Lett. 2003;32:690-3. 